\title{
Microstructural Characterization of SS304 upon Various Shot Peening Treatments
}

\author{
Yinsheng He, Kejian Li, In Shik Cho ${ }^{1}$, Chang Soon Lee ${ }^{1}$, In Gyu Park ${ }^{1}$, \\ Jung-il Song ${ }^{2}$, Cheol-Woong Yang ${ }^{3}$, Je-Hyun Lee, Keesam Shin* \\ School of Nano and Advanced Materials Engineering, Changwon National University, Changwon 51140, Korea \\ ${ }^{1}$ Department of Hybrid Engineering, Sunmoon University, Asan 31460, Korea \\ ${ }^{2}$ Department of Mechanical Engineering, Changwon National University, Changwon 51140, Korea \\ ${ }^{3}$ School of Advanced Materials Science and Engineering, Sungkyunkwan University, Suwon 03063, Korea
}

*Correspondence to:

Shin K,

Tel: +82-55-213-3696

Fax: +82-55-261-7017

E-mail: keesam@changwon.ac.kr

Received June 26, 2015

Revised August 11, 2015

Accepted August 11, 2015
Plastic deformation was introduced to the austenitic $(\gamma)$ stainless steel of SS304 by air blast shot peening, ultrasonic shot peening, and ultrasonic nanocrystalline surface modification. Various deformation structures were formed. The hardness, the deformation structure and the underlying grain refinement mechanism were investigated. In the deformed region, planar dislocation arrays and deformation twin (DT), the DT-DT intersection and $\varepsilon$-martensite structures, and $\alpha^{\prime}$-martensite were formed in the respective regions of low, medium, and high strain. The grain refinement mechanism is found to be closely related to the 1) sub-division of coarse grains by DT, shear bands and their intersection, and 2) formation of nano-sized $\alpha^{\prime}$-martensite due to the high plastic deformation.

Key Words: Austenitic stainless steel, Plastic deformation, Shot peening, Grain refinement, Transmission electron microscopy

\section{INTRODUCTION}

In the majority of cases, material failure initiates from the surface because of fatigue, creep, wear, corrosion, etc. Thus, optimizing the surface microstructure enhances the general behavior of a material in terms of fatigue life, friction, wear, corrosion and even tomography, and also its lifetime.

Thanks to intensive and extensive studies on nanostructured metals in the past several decades, the beneficial effects of optimizing nanostructure of metals and alloys have become more and more obvious (Gleiter, 2000; Meyers et al., 2006), e.g., ultra-high hardness and strength (Liu et al., 2013), enhanced physical properties (Lu et al., 2004), enhanced corrosion resistance (Lee et al., 2009).

Fabrication of a nanostructure on the surface of a bulk metal can involve either coating it with a dense, hard film creating a surface alloy, or inducing a phase transformation via plastic deformation such as a strain induced surface grain refinement (Mayer et al., 2012), or also nano crystallization ( $\mathrm{Lu} \& \mathrm{Lu}$, 2004; Zhong et al., 2010). Of course, even the combination of the methods can be used for some specific applications (Du et al., 2009; Hong et al., 2011).

Shot peening technologies have been used for a long time and are proven to be an effective method for introducing severe plastic deformation to the surface region, thereby refining and possibly nanocrystallizing the surface microstructure (Tong et al., 2003; Umemoto et al., 2003; Suh et al., 2007). One such method, air blast shot peening (ABSP), utilizes hard balls (tungsten carbide) for the energy transfer from compressed air to the surface of the work pieces. ABSP is a very flexible technology and is normally used in a cast factory to clear and strengthen the surface of the castings. However, little is known

This work was supported by the National Research Foundation of Korea (NRF) grant funded by the Korea government (MSIP) (No. 2011-0030058).

@ This is an open-access article distributed under the terms of the Creative Commons Attribution Non-Commercial License (http://creativecommons.org/licenses/by-nc/4.0) which permits unrestricted noncommercial use, distribution, and reproduction in any medium, provided the original work is properly cited.

Copyrights (C) 2015 by Korean Society of Microscopy 
about the microstructural evolution of the metals upon ABSP (Tan et al., 2000; Umemoto et al., 2003). Ultrasonic shot peening (USP) uses a high energy and high frequency (20 $\mathrm{kHz}$ ) ultrasonic generator as the energy source. The ultrasonic generator transfers the energy by the vibration of the hard balls that strike the surface of the work pieces in multiple directions (Liu \& Lu, 2000). For this, there are extensive reports on the microstructural refinement and property enhancement (Liu \& Lu, 2000; Zhang et al., 2003; Guo et al., 2004; Roland et al., 2006; Lu \& Hansen, 2009; Lee et al., 2013). Ultrasonic nanocrystalline surface modification (UNSM) is a recently developed (Suh et al., 2007; Yu et al., 2009; Amanov et al., 2012) and commercialized technique. The energy source of UNSM is similar to the USP; however, except that the UNSM has more control on the distances on the spots peened. The energies are transferred to the work pieces by a single hard ball/tip connected to a horn. The tip, with the energy of the ultrasonic generator and static load strikes the surface of work piece more than 20,000 times/s with 1,000 to 100,000 shots $/ \mathrm{mm}^{2}$. The respective strain rates of the ABSP, USP, and UNSM are estimated to be $\sim 10^{6}$ (Umemote et al., 2003), $10^{2}$ to $10^{3}$ (Lu \& Hansen, 2009) and $10^{3}$ to $10^{5} \mathrm{~s}^{-1}$ (He et al., 2014), depending on the process parameters. However, the ABSP and USP are more flexible than the UNSM, which is mostly used to modify the work pieces with more complicated shape such as gears, various bearings, tools, etc.

Shot peening produces a gradient strain from the treated surface into the deep matrix, inducing depth-dependent microstructures. Investigation of the gradient microstructure typically requires electron-microscopic analyses of the plan-view and cross-sectional specimens. Typical thinning procedures of the plan-view and X-transmission electron microscope (TEM) specimen for TEM observation include slicing, face-to-face bonding of the treated surfaces, dimpling, and final ion milling. It is well known that the pre- and finalthinning processes are time consuming and involve probable microstructural damage.

To date, various deformation microstructures, as well as microstructural refinement, have been reported in engineered stainless steel with low stacking fault energy (SFE, estimated to be $16.8 \mathrm{~mJ} / \mathrm{m}^{2}$; Zhang et al., 2003). For example, planar dislocation arrays (PDA) and deformation twin (DT) with
DT-DT intersections are the primary deformation microstructures. This is related to the introduction of low angle grain boundaries, increase of grain misorientation, turning to high angle grain boundaries with random misorientation, followed by sub-division of the original coarse grain into an even smaller one (Liu \& Lu, 2000; Zhang et al., 2003). Chen et al. (2011) reported the nucleation of the strain induced $\varepsilon$ and $\alpha^{\prime}$-martensite transformation as well as a deformation mechanism of the $\gamma \rightarrow$ DT, $\gamma \rightarrow \varepsilon$, and $\gamma \rightarrow \alpha^{\prime}$ depending on the calculated strain rate. An interesting deformation microstructure was the formation of a third-directional DT which cut the two-directional DT-DT intersections. This is considered to be the main grain refinement mechanism as proposed by Lu et al. (2010). Even though various deformation microstructures have been reported in the surface of the deformed stainless steels, more comprehensive studies of the shot peening induced depth-dependent structures still needs to be done.

In this work, plastic deformation is introduced to an austenitic $(\gamma)$ stainless steel (SS304) by using the ABSP, USP, or UNSM techniques. The objectives of this study are 1) development of efficient time-saving, damage-free, and positional specific thinning method of plan-view and cross-sectional specimens for TEM observation, 2) characterization and determination of the effect of strain on the deformation microstructure, 3 ) understanding the underlying grain refinement mechanism, and 4) determination of the differences among the deformed microstructures of the three shot peening techniques.

\section{MATERIALS AND METHODS}

\section{Materials and Process}

Materials used in this work are a commercial SS304 with a plate of the $130 \times 40 \times 5 \mathrm{~mm}^{3}$. The chemical composition is, as per the AISI304 standard of $\sim 0.08 \% \mathrm{C}, \sim 1 \% \mathrm{Si}, \sim 2 \% \mathrm{Mn}$, $\sim 0.045 \% \mathrm{P}, \sim 0.03 \% \mathrm{~S}, 8 \% \mathrm{Ni} \sim 10.5 \% \mathrm{Ni}, 18 \% \mathrm{Cr} \sim 20 \% \mathrm{Cr}$, with Fe making up the rest. Prior to shot peening, the surface of the plate was mechanically polished with up to 1,200-grid sandpaper.

Various samples were treated by the ABSP, USP, or UNSM with different peening parameters (Table 1). It is difficult to select the samples with same energy dispersion since

Table 1. The shot peening parameters of the specimens

\begin{tabular}{|c|c|c|c|c|c|c|c|c|}
\hline \multicolumn{2}{|c|}{ Shot peening } & \multicolumn{7}{|c|}{ Processing condition } \\
\hline No. & Process & Frequency $(\mathrm{kHz})$ & Amplitude $(\mu \mathrm{m})$ & Static load (kgf) & Speed (rpm) & Feed rate $(\mathrm{mm} / \mathrm{rev})$ & Ball/tip diameter (mm) & Remark \\
\hline 1 & Unpeened & - & - & - & - & - & - & - \\
\hline 2 & ABSP & - & - & - & - & - & 0.8 & $0.33 \mathrm{mmA}$ \\
\hline 3 & USP & 20 & 50 & - & - & - & 2 & $105 \mathrm{~s}$ \\
\hline 4 & UNSM & 20 & 50 & 5 & 20 & 0.07 & 2.3 & - \\
\hline
\end{tabular}

ABSP, air blast shot peening; USP, ultrasonic shot peening; UNSM, ultrasonic nanocrystalline surface modification. 
this depends on too many parameters, including treatment time in ABSP, peening time, amplitude and ball size in USP, amplitude and all parameters in UNSM. In addition, impact directions vary from one-, multi-, or two- directions for ABSP, USP, and UNSM, respectively (Lu \& Hansen, 2009). Thus, ABSP treated samples are chosen to have a deformation depth similar to that of the USP sample (see the hardness results in "Surface Analysis" of RESULTS AND DISCUSSION), whereas the UNSM specimens are chosen to have about the same frequency, amplitude, and ball size.

\section{Microstructural Characterization}

After shot peening, the surface region of the specimens was analyzed using scanning electron microscope (SEM), X-ray diffractometer (XRD), and TEM. SEM observations were carried out on a JSM-5610 SEM (JEOL, Japan) operated at an accelerating voltage of $20 \mathrm{keV}$. XRD analyses of the surface layer were performed on a Philips X'pert MPD X- ray (Philips, Netherlands) diffractometer with the $\mathrm{CuK}_{\alpha 1}$ radiation. The top-most specimens for TEM study were prepared by a modified jet-polishing method as detailed in He et al. (2014). In brief, after careful polishing of the $3 \mathrm{~mm}$ disk down to $60 \mu \mathrm{m}$ from the untreated side, the treated surface was then covered by a protective light-transparent plastic film, which was then electropolished and stopped just before the perforation. Then, the thinning of the sample was completed by final polishing of both sides, i.e., by the twin jets of $5 \%$ perchloric acid and $95 \%$ acetic acid.

Cross-sectional analyses of the samples were carried out with electron backscatter diffraction (EBSD) and TEM. EBSD mapping was carried out on the field emission (FE)SEM (MIRA II; TESCAN, Czech) equipped with a TSL-OIM system (EDAX, USA) in which the specimens were prepared by final polishing in the colloidal silica suspensions for a period of two hours. The EBSD measurements were carried out with a step size of $0.2 \mu \mathrm{m}$ and exposure speed of 120.5 frames/s. Data with a confidence index value of $<0.2$ were "cleaned up" by using the supported OIM analysis program (EDAX).

TEM analysis was performed on a JEOL JEM-2100F (JEOL) microscope, operating at $200 \mathrm{keV}$. Cross-sectional TEM (X-TEM) specimens were also prepared with the use of a modified method by optimizing the parameters of jetpolishing. After face-to-face bonding, the specimens were jet polished until the appearance of the hole near the interface. In some cases, ion milling was used for final thinning (to obtain an even larger thin area) of the specimen. The methods mentioned here for preparation of the plan-view and crosssectional are found to be very efficient, and possibly have larger thin area than the traditional process. Simulation and precise analyses of the selected area diffraction pattern (SADP) were carried out by utilizing CaRine Crystallography (of which the models were built based on the XRD results on the lattice parameters) and Gatan Digital Microscopy (Gatan, USA) and Image-Pro Plus software (Media Cybernetics, USA).
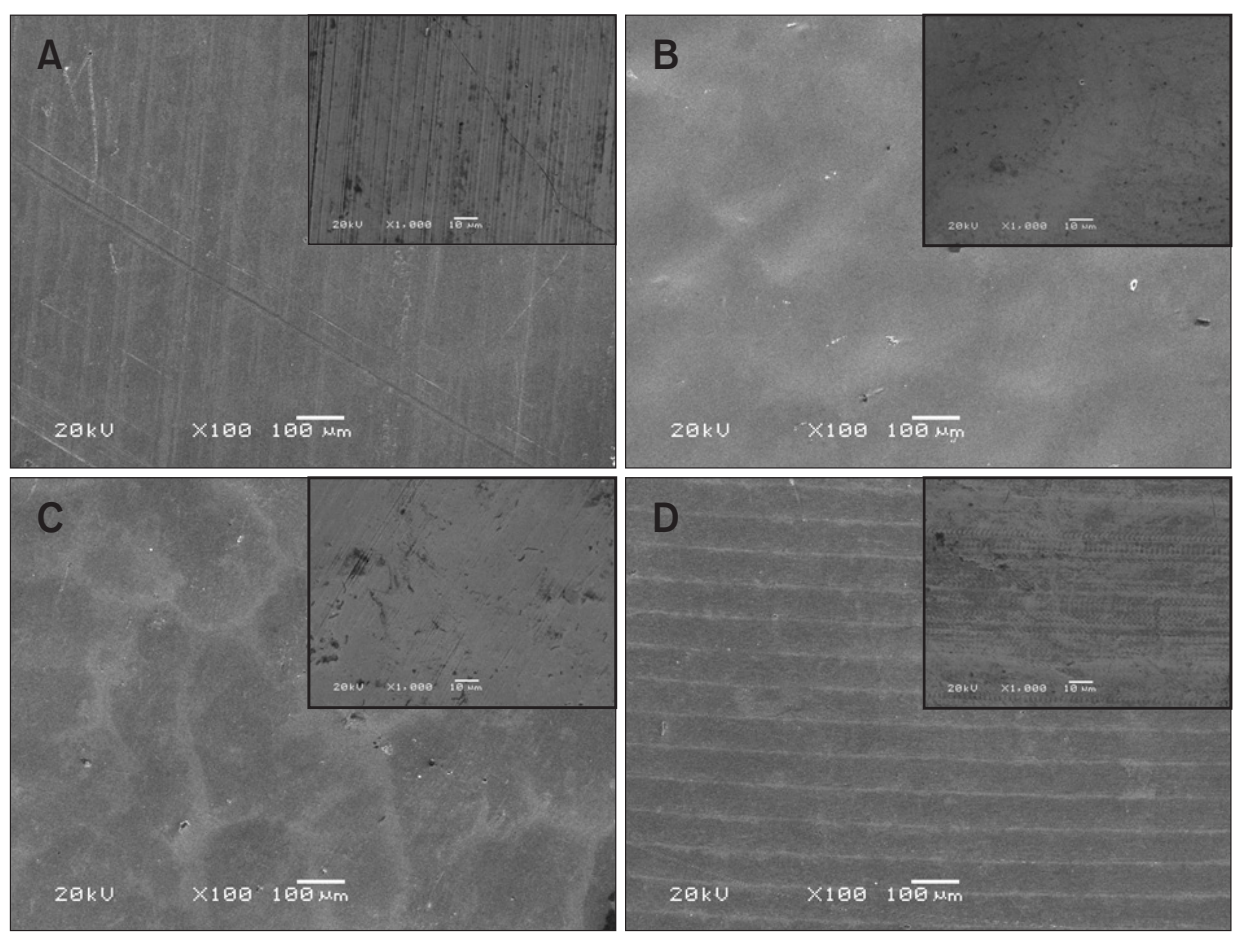

Fig. 1. Scanning electron microscope (SEM) images of the surface of the SS304 specimens: untreated (A), air blast shot peening treated (B), ultrasonic shot peening (C), and ultrasonic nanocrystalline surface modification treated (D). Insets are magnified SEM images. 


\section{RESULTS AND DISCUSSION}

\section{Surface Analysis}

\section{SEM analysis}

Fig. 1 shows surface SEM images of the unpeened and

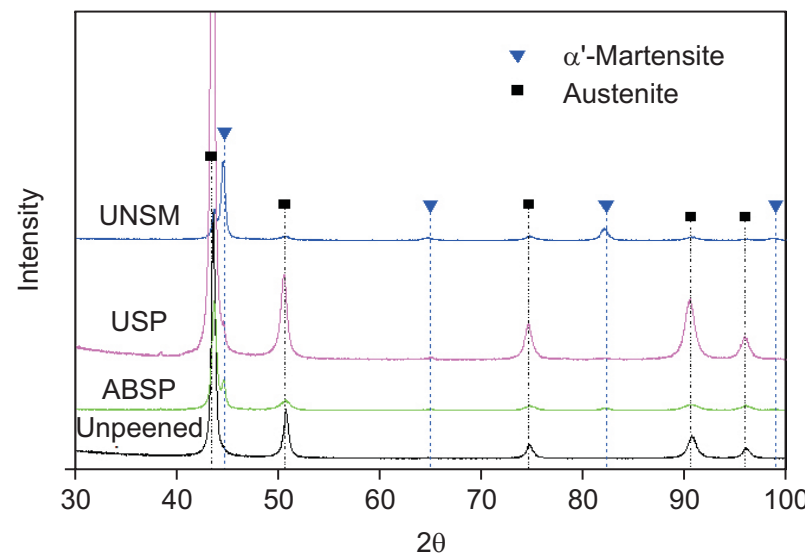

Fig. 2. X-ray diffractometer profiles of the untreated, air blast shot peening (ABSP), ultrasonic shot peening (USSP), and ultrasonic nanocrystalline surface modification (UNSM) treated SS304 specimens. shot peened specimens. Fig. 1A shows a surface with some scratches introduced by mechanical polishing. After peening (Fig. 1B) the surface cracks and pores are gone. Many microdimples were formed on the ABSP and USP treated specimens (Fig. 1B-D). However, racetrack like pattern with tread marks appeared on the surface after fabrication (Fig. 1D and in the set), which may improve the tribological performance (Amanov et al., 2012).

\section{$X R D$ analysis}

Fig. 2 and Table 2 show the XRD patterns and the corresponding calculated lattice parameters of the untreated and shot peened specimens. The unpeened specimen has austenite (fcc, $\mathrm{a}=3.59 \AA$ ) structure. Clearly, $\alpha^{\prime}$-martensite (bcc, $\mathrm{a}=2.87 \AA$ ) was formed upon shot peening, mostly on the surface layers of the shot peened specimens. Unlike the complete $\alpha^{\prime}$ transformation in a SS304 specimen treated by surface mechanical attrition treatment (SMAT) (Zhang et al., 2003), only a partial transformation occurs in this case. Based on the XRD results, the lattice parameters and $d_{h k l}$ of each plane were calculated and are listed in Table 2. They are used for the analyses of the SADP in the following sections. We note that the strain induced $\varepsilon$-martensite (hcp, structure) transformation has always been observed in shot

Table 2. X-ray diffractometer results on the $d_{h k l}$ and lattice parameters of the phase in the untreated and treated specimens

\begin{tabular}{|c|c|c|c|c|c|c|c|c|}
\hline & (a) & $2 \theta$ & $(h k l)$ & $d(\AA)$ & (a) & $2 \theta$ & $(h k l)$ & $d(\AA)$ \\
\hline \multirow[t]{5}{*}{ Unpeened } & $\gamma$ & 43.58 & 111 & 2.08 & - & & & \\
\hline & $(3.59)$ & 50.70 & 200 & 1.80 & & & & \\
\hline & & 74.72 & 220 & 1.27 & & & & \\
\hline & & 90.66 & 311 & 1.08 & & & & \\
\hline & & 95.94 & 222 & 1.04 & & & & \\
\hline \multirow[t]{5}{*}{ ABSP } & $\gamma$ & 43.66 & 111 & 2.07 & $\alpha^{\prime}$ & 44.56 & 110 & 2.03 \\
\hline & (3.59) & 50.60 & 200 & 1.80 & $(2.87)$ & 65.00 & 200 & 1.43 \\
\hline & & 74.56 & 220 & 1.27 & & 82.17 & 211 & 1.17 \\
\hline & & 90.60 & 311 & 1.08 & & 99.01 & 220 & 1.01 \\
\hline & & 96.02 & 222 & 1.04 & & & & \\
\hline \multirow[t]{5}{*}{ USP } & $\gamma$ & 43.48 & 111 & 2.08 & $\alpha^{\prime}$ & 44.58 & 110 & 2.03 \\
\hline & $(3.60)$ & 50.51 & 200 & 1.81 & $(2.87)$ & 65.00 & 200 & 1.43 \\
\hline & & 74.60 & 220 & 1.27 & & 82.23 & 211 & 1.17 \\
\hline & & 90.50 & 311 & 1.08 & & 98.75 & 220 & 1.01 \\
\hline & & 95.80 & 222 & 1.04 & & & & \\
\hline \multirow[t]{10}{*}{ UNSM } & $\gamma$ & 43.64 & 111 & 2.07 & $\alpha^{\prime}$ & 44.54 & 110 & 2.03 \\
\hline & (3.59) & 50.70 & 200 & 1.80 & (2.87) & 64.76 & 200 & 1.44 \\
\hline & & 74.72 & 220 & 1.27 & & 82.06 & 211 & 1.17 \\
\hline & & 90.62 & 311 & 1.08 & & 98.56 & 220 & 1.02 \\
\hline & & 95.90 & 222 & 1.04 & & & & \\
\hline & & & & & $\varepsilon$ & 42.3 & 100 & 2.13 \\
\hline & & & & & $2.47,4.05$ & 44.72 & 002 & 2.02 \\
\hline & & & & & & 48.15 & 101 & 1.88 \\
\hline & & & & & & 63.24 & 102 & 1.49 \\
\hline & & & & & & 77.36 & 110 & 1.23 \\
\hline
\end{tabular}

The lattice parameters of $\varepsilon$ are from ICDD (international centre for diffraction data) card.

ABSP, air blast shot peening; USP, ultrasonic shot peening; UNSM, ultrasonic nanocrystalline surface modification. 
peened and severely deformed stainless steel (Lee \& Lin, 2000; Nakada et al., 2010; Chen et al., 2011). However, XRD shows no evidence of the $\varepsilon$-martensite transformation in the shot peened specimens, which is ascribed to the low volume of the $\varepsilon$-martensite. The lattice parameters, with corresponding $d$-spaces, were retrieved from the literature and are given in Table 2 (Datta et al., 2009). The broad diffraction peaks (both of the $\gamma$ and $\alpha^{\prime}$ ) indicate the formation the nanocrystalline regions in the surface of the shot peened specimens.

\section{TEM analysis}

Fig. 3 shows the TEM images of the untreated specimens. Here one can see the coarse grain structure (Fig. 3A) with some dislocations in various slip systems (inset SADP with the
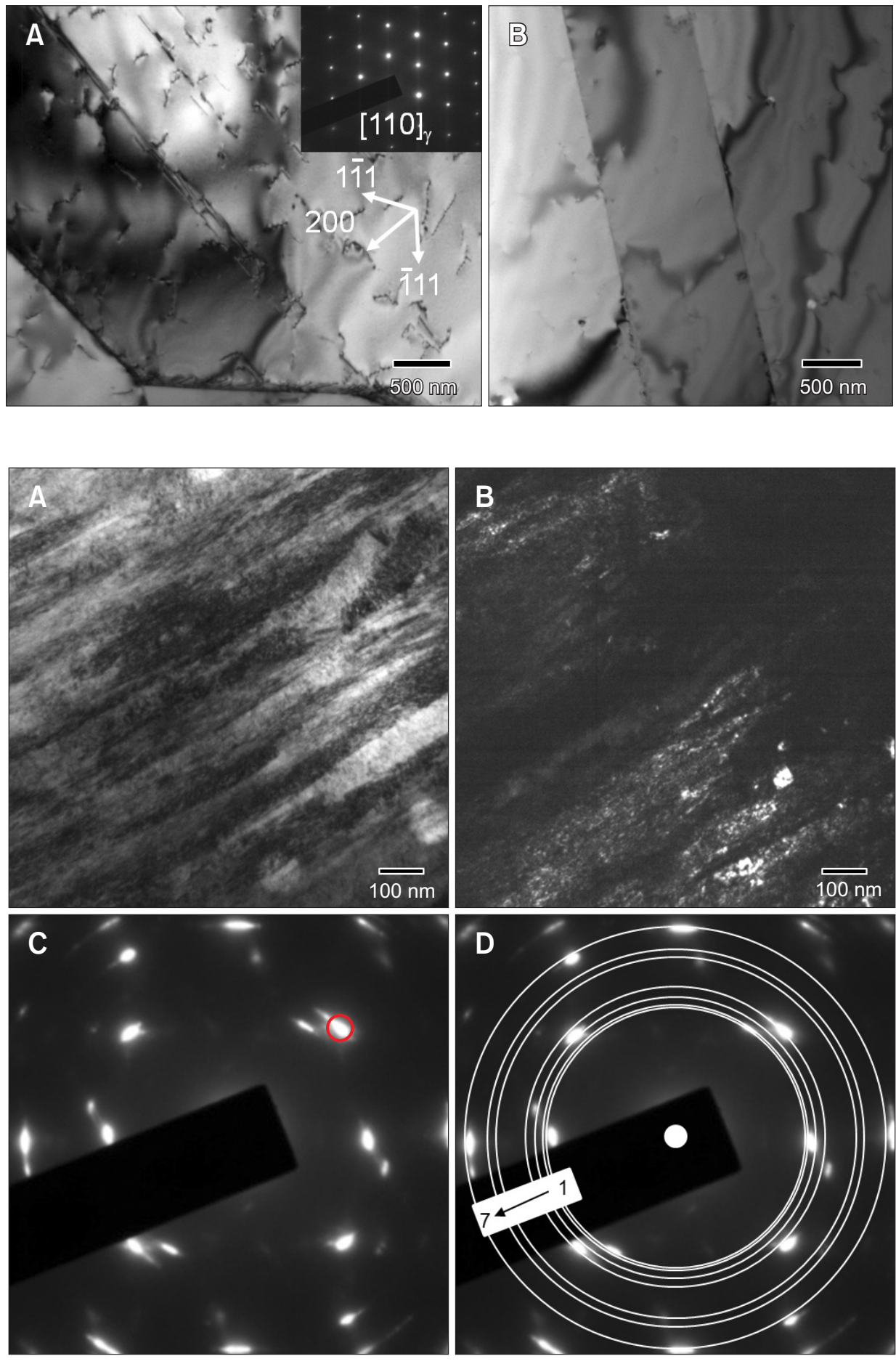

Fig. 3. Transmission electron microscope images of the untreated SS304 specimen: coarse grain and defects (A) and annealing twin (B).
Fig. 4. Plan-view bright field (A) and dark field (B) transmission electron microscope images with its selected area diffraction pattern (SADP) (C) and the indexed SADP (D) of the top surface of the air blast shot peening treated SS304 specimen. Dark field image was recorded under the diffracted beam of the marked region in Fig. 4C. 


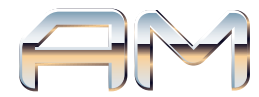

He Y et al.
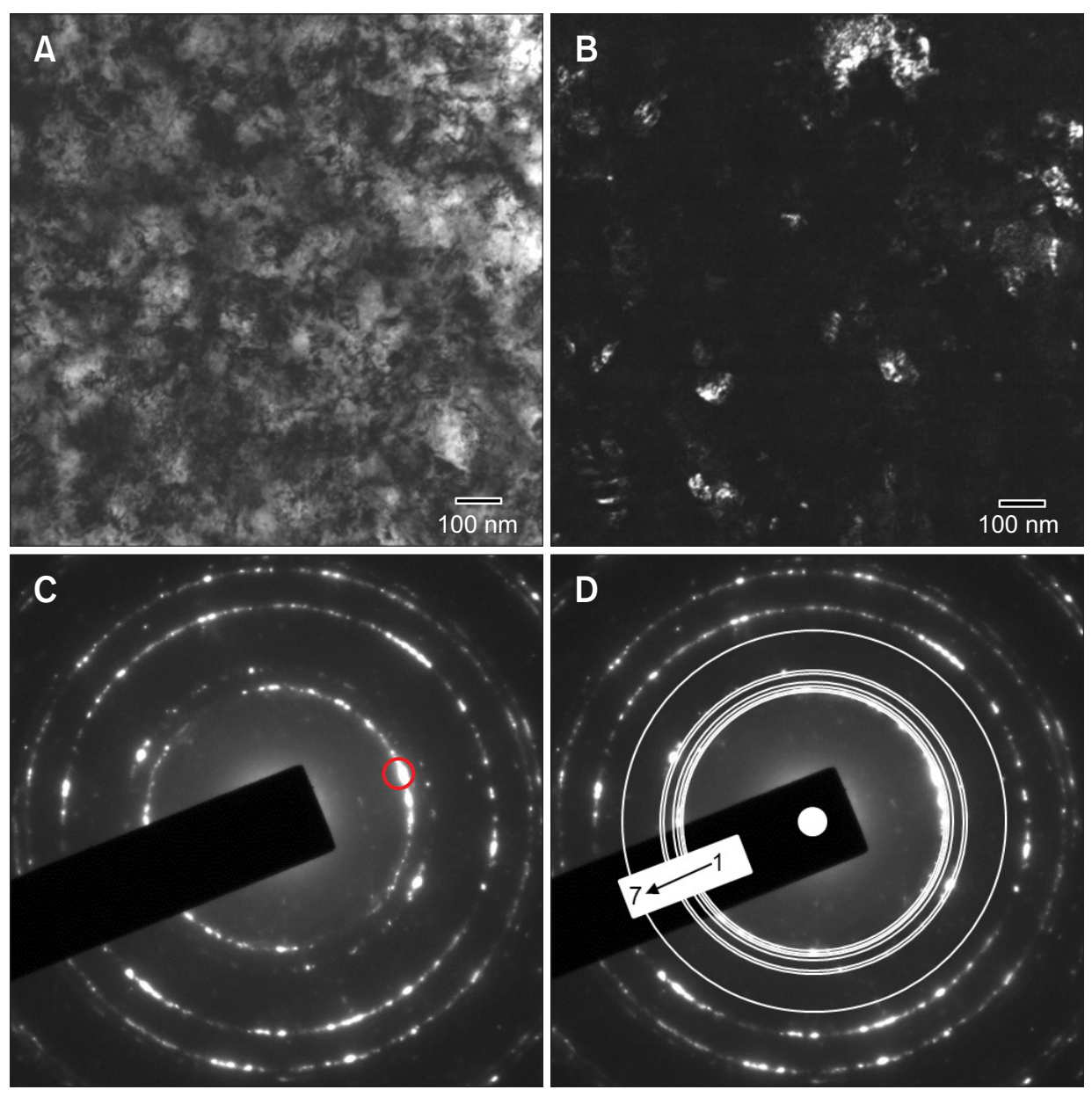

Fig. 5. Plan-view bright field (A) and dark field (B) transmission electron microscope images with its selected area diffraction pattern (SADP) (C) and the indexed SADP (D) of the top surface of the ultrasonic shot peening treated specimen. Dark field image was recorded under the diffracted beam of the marked region in Fig. 5C.

indexing), stacking fault, and annealing twin (Fig. 3B). Most of the images were recorded with a $[110]_{\gamma}$ beam direction.

Fig. 4-6 are plan-view TEM images taken at the topmost surface of the shot peened specimens. The microstructure of the topmost surface is characterized by the distributed nanograins $(<100 \mathrm{~nm})$, as shown in the bright field (BF) and dark field (DF) TEM images (Fig. 4A and B, Fig. 5A and B, and Fig. 6A and B). The corresponding SADPs (Fig. 4C, Fig. 5C, and Fig. 6C) display scattered spots with partial rings that indicate the formation of the fine substructures of various orientations different from those of the original grains. A detailed analysis of the SADP (Fig. 4D, Fig. 5D, and Fig. 6D) was carried out by matching the $d$-space calculated from the SADPs (1 7 as noted) with the results calculated by XRD (Table 2), whose results are shown in Table 3. For example, as shown in Fig. 6C, the diffracted rings and spots in the "(1)" and "(2)" regions are broad and scattered, suggesting the presence of $\gamma, \alpha^{\prime}$-, and $\varepsilon$-martensite in the top-most layer of the shot peened specimens.

The above results indicate the improvement of the surface morphologies, and the refinement of the original coarse $\gamma$ grain, and formation of the newly nucleated $\alpha^{\prime}$ - and $\varepsilon$-mar- tensite by means of various shot peening methods.

\section{Cross-sectional Analysis by Microhardness Testing and EBSD}

Fig. 7 shows the cross-sectional microhardness profile of the unpeened and shot peened specimens. Obviously, the surface hardness is increased by the shot peening up to $\sim 400 \mu \mathrm{m}$ in the ABSP and USP peened specimens, and $\sim 700 \mu \mathrm{m}$ in the UNSM treated one. Careful observation may reveal that in the top-most surface, the hardness in the ABSP peened specimen is little bit lower than the others, while the USP and UNSM specimens have similar values. The lower hardness in the surface of the ABSP treated specimens is considered to be the reason for the refined nanostructure being larger than that of the ABSP and UNSM treated specimens as can be seen in Fig. 4 to 6 . On the other hand, the decreasing slope of the hardness to the original value is slower in the UNSM specimen.

Fig. 8 shows the cross-sectional EBSD images of the unpeened and shot peened specimens. In Fig. 8A1 and Fig. 8B1, the untreated samples show a relatively homogenous microstructure. Only a few DT can be observed in the very top surface region $(\sim 15 \mu \mathrm{m}$ in depth), which were probably intro- 

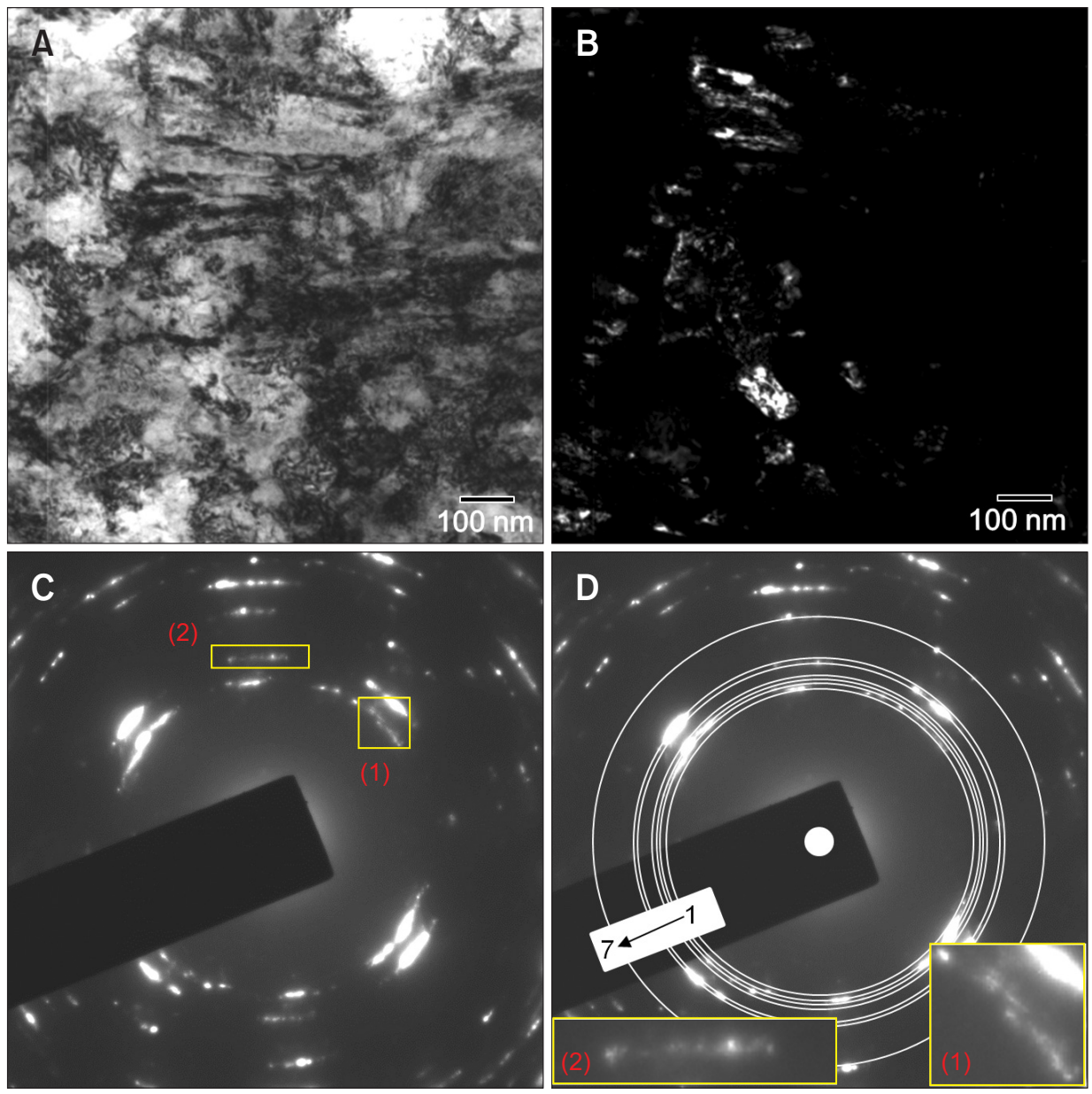

Fig. 6. Plan-view bright field (A) and dark field (B) transmission electron microscope images with the selected area diffraction pattern (SADP) (C) and the indexed SADP (D) of the top surface of the ultrasonic nanocrystalline surface modification treated specimen. Dark field image is from the diffracted beam of the marked region in Fig. 6C. "(1)" and "(2)" in Fig. 6D are the enlarged images of the marked region "(1)" and "(2)" in Fig. 6C.

Table 3. Transmission electron microscope selected area diffraction pattern results on the $d_{h k l}$ and phase in the treated SS304 specimens

\begin{tabular}{|c|c|c|c|c|c|c|c|c|c|c|c|c|c|c|c|}
\hline \multirow{2}{*}{ No. } & \multicolumn{5}{|c|}{ ABSP } & \multicolumn{5}{|c|}{ USP } & \multicolumn{5}{|c|}{ UNSM } \\
\hline & $\mathrm{r}\left(\mathrm{nm}^{-1}\right)$ & $d(\AA)$ & $\gamma$ & $\alpha^{\prime}$ & $\varepsilon$ & $\mathrm{r}\left(\mathrm{nm}^{-1}\right)$ & $d(\AA ̊)$ & $\gamma$ & $\alpha^{\prime}$ & $\varepsilon$ & $\mathrm{r}\left(\mathrm{nm}^{-1}\right)$ & $d(\AA)$ & $\gamma$ & $\alpha^{\prime}$ & $\varepsilon$ \\
\hline 1 & 4.68 & 2.14 & & & 100 & 4.66 & 2.14 & & & 100 & 4.60 & 2.18 & & & 100 \\
\hline 2 & 4.78 & 2.09 & 111 & & & 4.73 & 2.11 & 111 & & & 4.77 & 2.10 & 111 & & \\
\hline 3 & 5.10 & 1.96 & & 110 & & 4.83 & 2.07 & & 110 & & 4.83 & 2.07 & & 110 & \\
\hline 4 & 5.39 & 1.86 & 200 & & & 4.98 & 2.01 & & & 002 & 4.98 & 2.01 & & & 002 \\
\hline 5 & 6.49 & 1.54 & & & 102 & 5.32 & 1.88 & & & 101 & 5.35 & 1.87 & & & 101 \\
\hline 6 & 6.80 & 1.47 & & 200 & & 5.43 & 1.84 & 200 & & & 5.44 & 1.84 & 200 & & \\
\hline 7 & 7.58 & 1.32 & 220 & & & 6.78 & 1.47 & & 200 & 102 & 6.70 & 1.49 & & 200 & 102 \\
\hline
\end{tabular}

ABSP, air blast shot peening; USP, ultrasonic shot peening; UNSM, ultrasonic nanocrystalline surface modification.

duced during the transition and pre-preparation process. In the shot peened specimens (Fig. 8B2-D1), a high density of intersected DT are formed within the coarse grain, in which the density decreases with increasing the depth from the top treated surface. In the layer near to the surface region, the presence of the dark region indicates that the grain size is below the resolution of the EBSD and suggests the formation of nano structures in this region. For the inverse pole figure images shown in Fig. 8B2-D2, the colors represent different orientations. The presence of all colors with similar frequencies indicates that all the specimens do not exhibit a strong texture, which means that the shot peening does not change the texture.

From a microstructural point of view, the change in the microstructure suggests that the deformation depth of ABSP, USP and UNSM is $\sim 120, \sim 150$, and $\sim 200 \mu \mathrm{m}$, respectively. These values are much smaller than those at the microhardness profiles, which also indicate that there should 
be some newly formed deformation structures that are below the detection limits of the EBSD, which strengthen the microstructures. Generally, the deformation depth was measured from the cross-sectional SEM. This indicates that the combination of the microhardness and EBDS analyses is an effective way to study the overall deformation depth and microstructural evolution (He et al., 2014).

\section{Detailed X-TEM Analysis}

Shot peening introduced a gradient microstructure on the surface as shown in Fig. 8B-D. The depth-dependence in the deformation structures is natural since the strain increases with decreasing depth (Tao et al., 2002; Zhang et al., 2003).

\section{Microstructural evolution in the ABSP specimen}

Fig. 9 shows the typical TEM micrographs at the depth of $\sim 150$ and $\sim 100 \mu \mathrm{m}$ from the top surface. At $\sim 150 \mu \mathrm{m}$ (Fig. $9 \mathrm{~A})$, the microstructure is characterized by a PDA in two

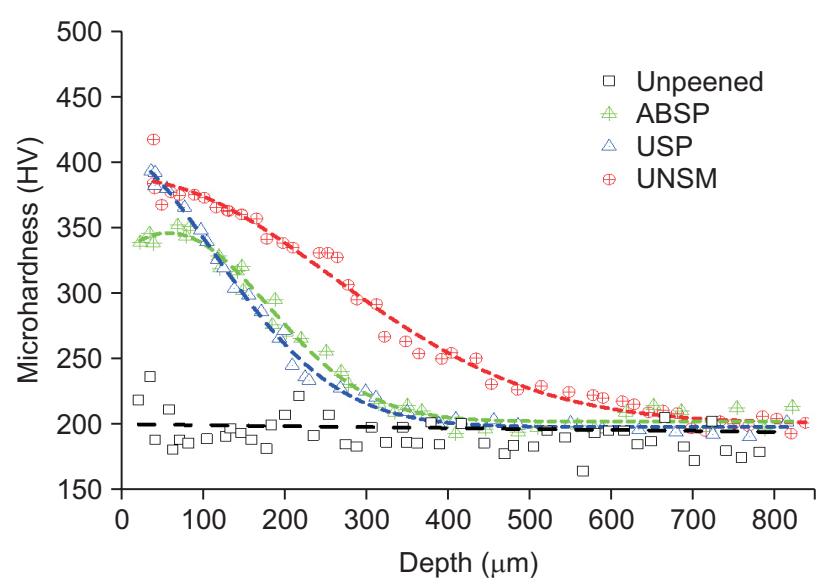

Fig. 7. Cross-sectional microhardness of the SS304 specimens. ABSP, air blast shot peening; USP, ultrasonic shot peening; UNSM, ultrasonic nanocrystalline surface modification. directions and that intersect at an angle of $72^{\circ}$, which is close to the angle expected between two (111) crystallographic planes of $\gamma$. The spacing between the PDA is in the range of 100 to $400 \mathrm{~nm}$. At $\sim 100 \mu \mathrm{m}$ depths (Fig. 9B), the DT-DT intersections typically have an angle of $\sim 72^{\circ}$. The inset SADP
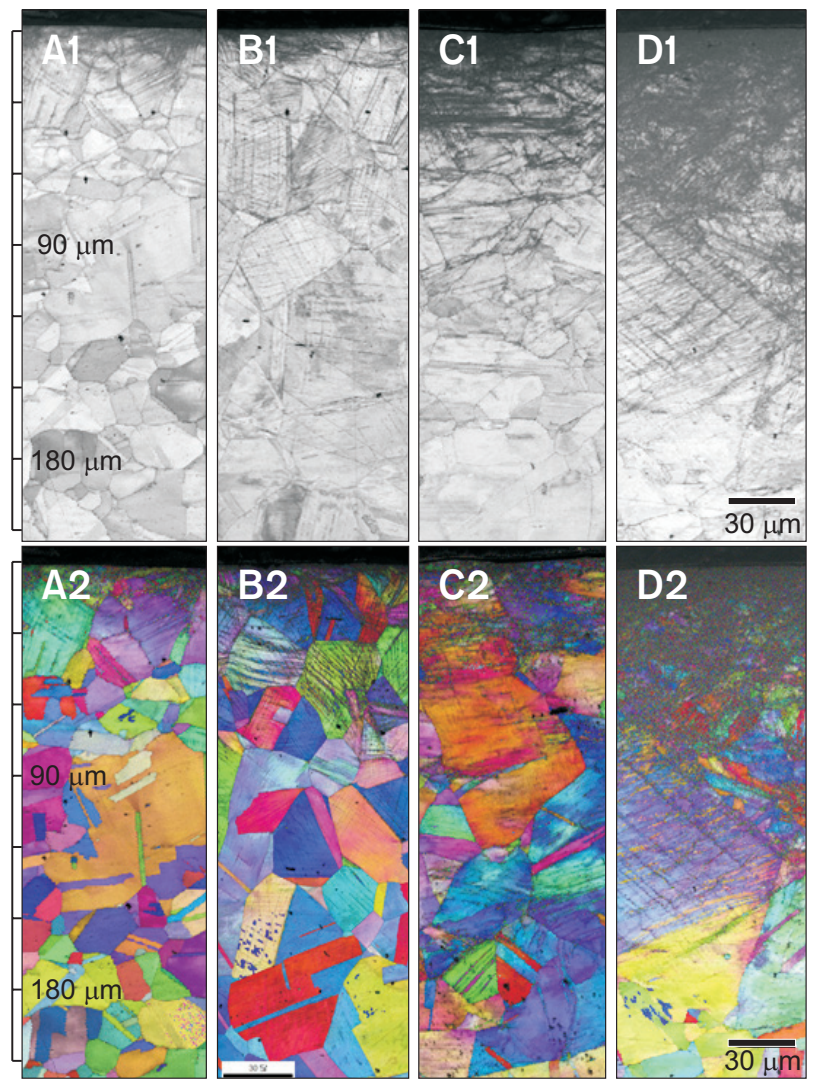

Fig. 8. Cross-sectional electron backscatter diffraction image quality (A1D1) and inverse pole figure (A2-D1) map images of SS304 specimens of the untreated (A1, B1), air blast shot peening (B1, B2), ultrasonic shot peening $(\mathrm{C} 1, \mathrm{C} 2)$ and ultrasonic nanocrystalline surface modification (D1, D2).
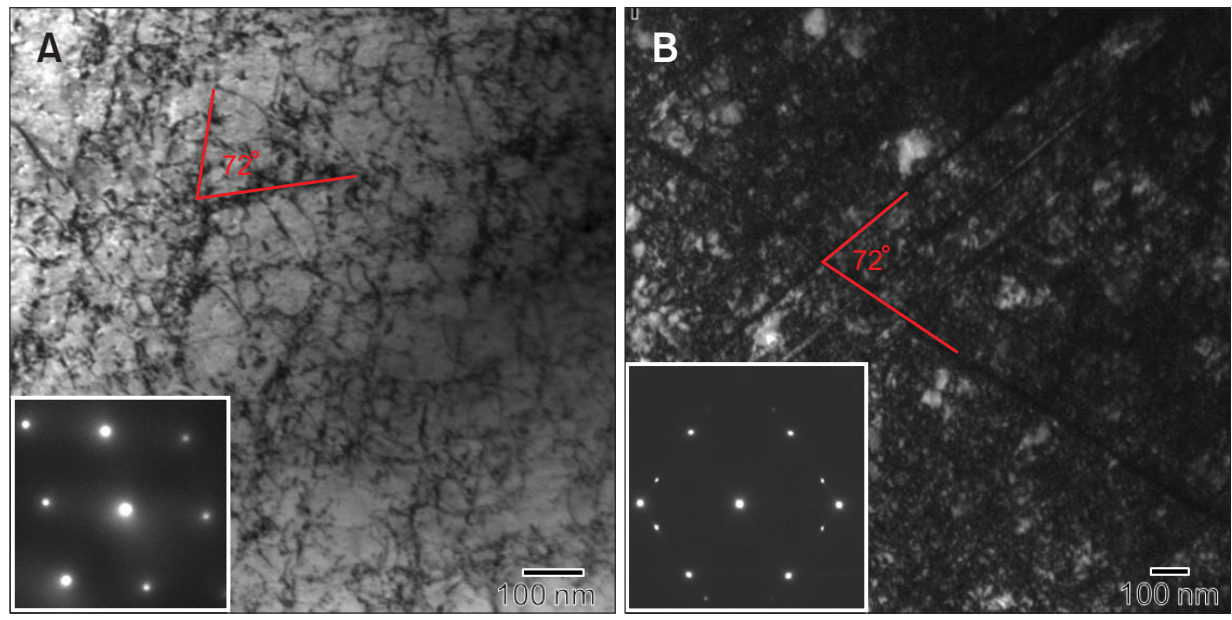

Fig. 9. X-transmission electron microscope images of the air blast shot peening treated specimen at the depth of $\sim 150 \mu \mathrm{m}$ (A), and $\sim 100 \mu \mathrm{m}$ (B) from the top treated surface. Insets are the corresponding selected area diffraction patterns. 

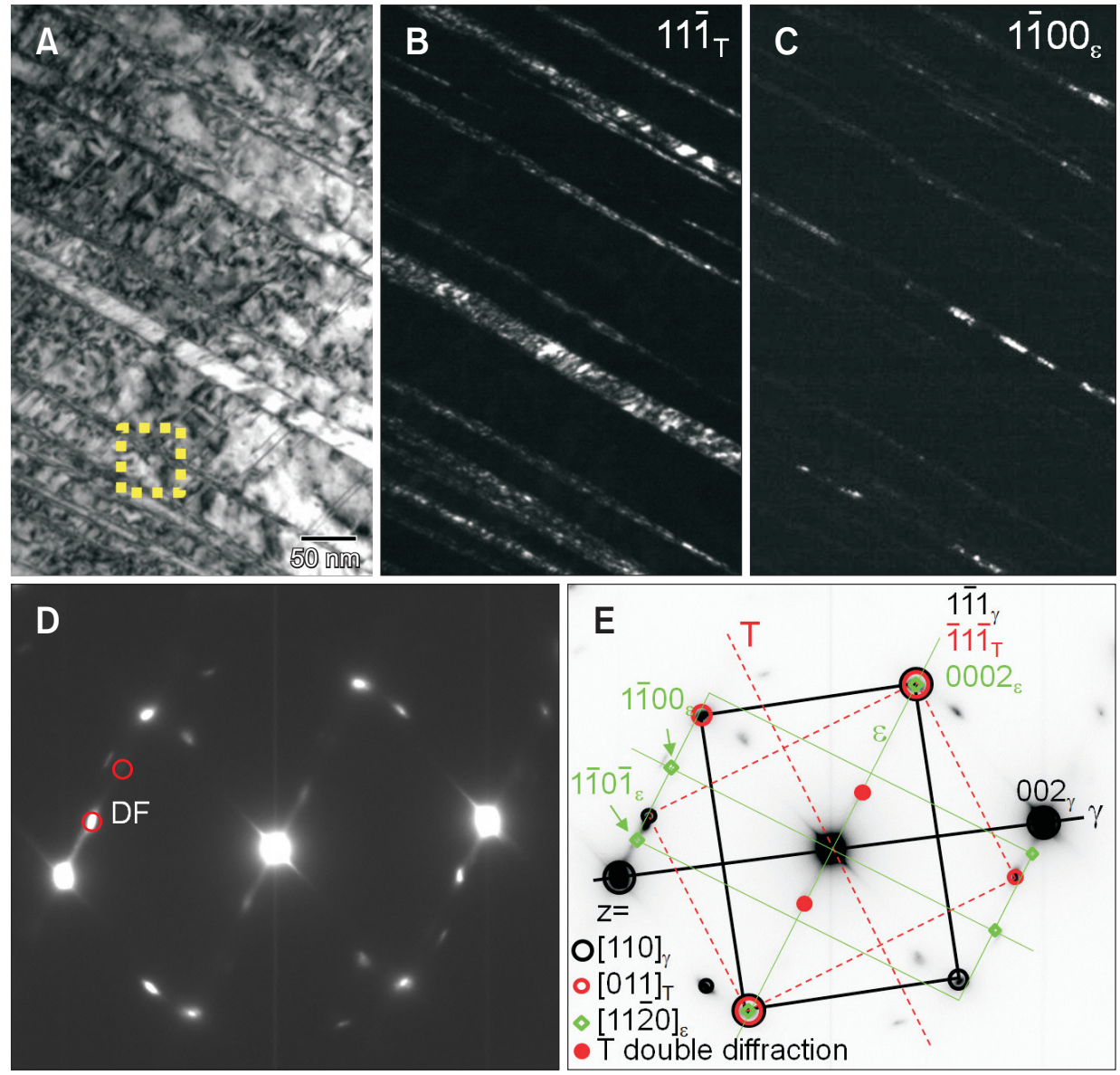

Fig. 10. X-transmission electron microscope (TEM) images of the air blast shot peening treated specimen at the depth of $\sim 80 \mu \mathrm{m}$ : bright field TEM (A), selected area diffraction pattern (SADP) (B), and corresponding indexed SADP $(\mathrm{C}), \mathrm{DF}$ TEM images (D, E), corresponding to the diffracted spots of $\varepsilon$ and twin (T) in Fig. $10 \mathrm{~B}$, respectively. DF, dark field. shows well-defined diffraction spots and superposition of the three sets of the $\langle 110\rangle$ diffraction, which is evidence for a twin-twin intersection in an fcc system. Dislocations in high densities are still visible within the grains (the blocks formed by the DT intersections). The observation of the DTDT intersections in shot peened stainless steel is similar to the reported results (Liu \& Lu, 2000; Zhang et al., 2003; Roland et al., 2006).

Fig. 10 is a set of TEM images that shows the typical microstructures observed at a depth of $\sim 80 \mu \mathrm{m}$ in ABSP treated specimens. Clearly, the BF TEM image and SADP (Fig. 10A and B) reveal the formation of large numbers of DT and at high density. The SADP was recorded by tilting the specimen along the beam direction of [110] $]_{\gamma}$. Fig. 10 shows the indexed SADP, comprised of $\gamma, \mathrm{T}$, and $\varepsilon$, with the zone axis of [110] $\gamma / /[011]_{\mathrm{T}} / /[11 \overline{2} 0]_{\varepsilon}$. The orientation relationship of the newly nucleated $\varepsilon$-martensite with the $\gamma$ and twin, observed here, agreed with the measurements on stainless steel deformed by SMAT (Chen et al., 2011), and fatigued at low temperature (Kruml et al., 2000), which is known as the S-N (ShojiNichiyama) relationship between $\mathrm{fcc}$ and hcp lattices. Fig. $10 \mathrm{D}$ and $\mathrm{E}$ are the DF TEM images of the twin and $\varepsilon$, which

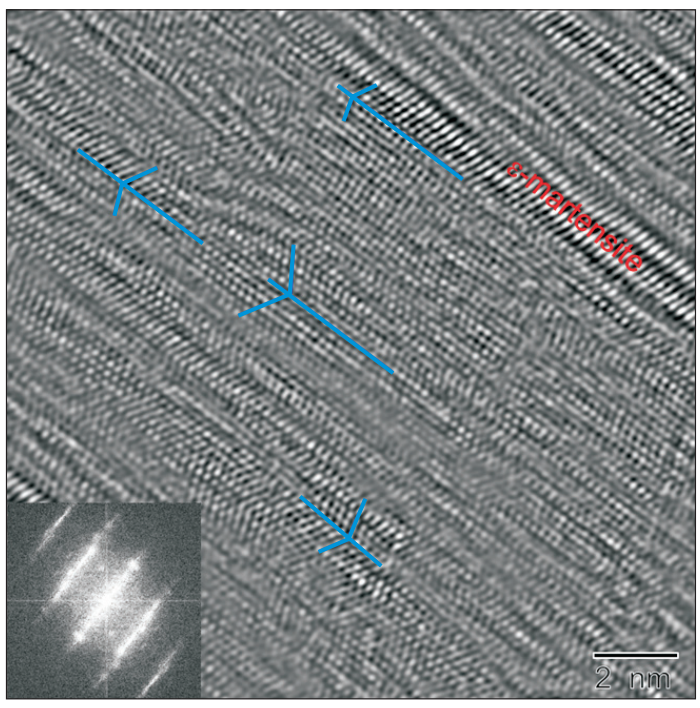

Fig. 11. Inverse fast Fourier transform (FFT) image of the high-resolution transmission electron microscopy images at a depth of $\sim 15 \mu \mathrm{m}$ from the top treated surface of the air blast shot peening treated specimen. Inset is the FFT. 
is imaged by the diffraction spots as marked in Fig. 10B. The DTs have a thickness of $\sim 40 \mathrm{~nm}$ (Fig. 10D). The $\varepsilon$-martensite plates, frequently observed within the DT, are very thin $(\sim 20$ $\mathrm{nm}$ ) as shown in Fig. 10E. A closer view of these structures is given in the inverse fast Fourier transform (FFT) image (Fig. 11), in which the high-resolution transmission electron microscopy image is recorded at the region outlined (dotted square) in Fig. 10A. Fig. 11 shows that some of the DT is nano-sized only with several lattice planes, and $\varepsilon$-martensite embryo in the DT. The inset FFT images, appearing as the diffuse spots, further confirm the presence of nano-sized DT. At the same depth $(\sim 80 \mu \mathrm{m})$, another frequently observed structure is the shear band (SB) (Liu \& Lu, 2000) with a thickness of $\sim 300 \mathrm{~nm}$, shown in Fig. 12A. The formation of
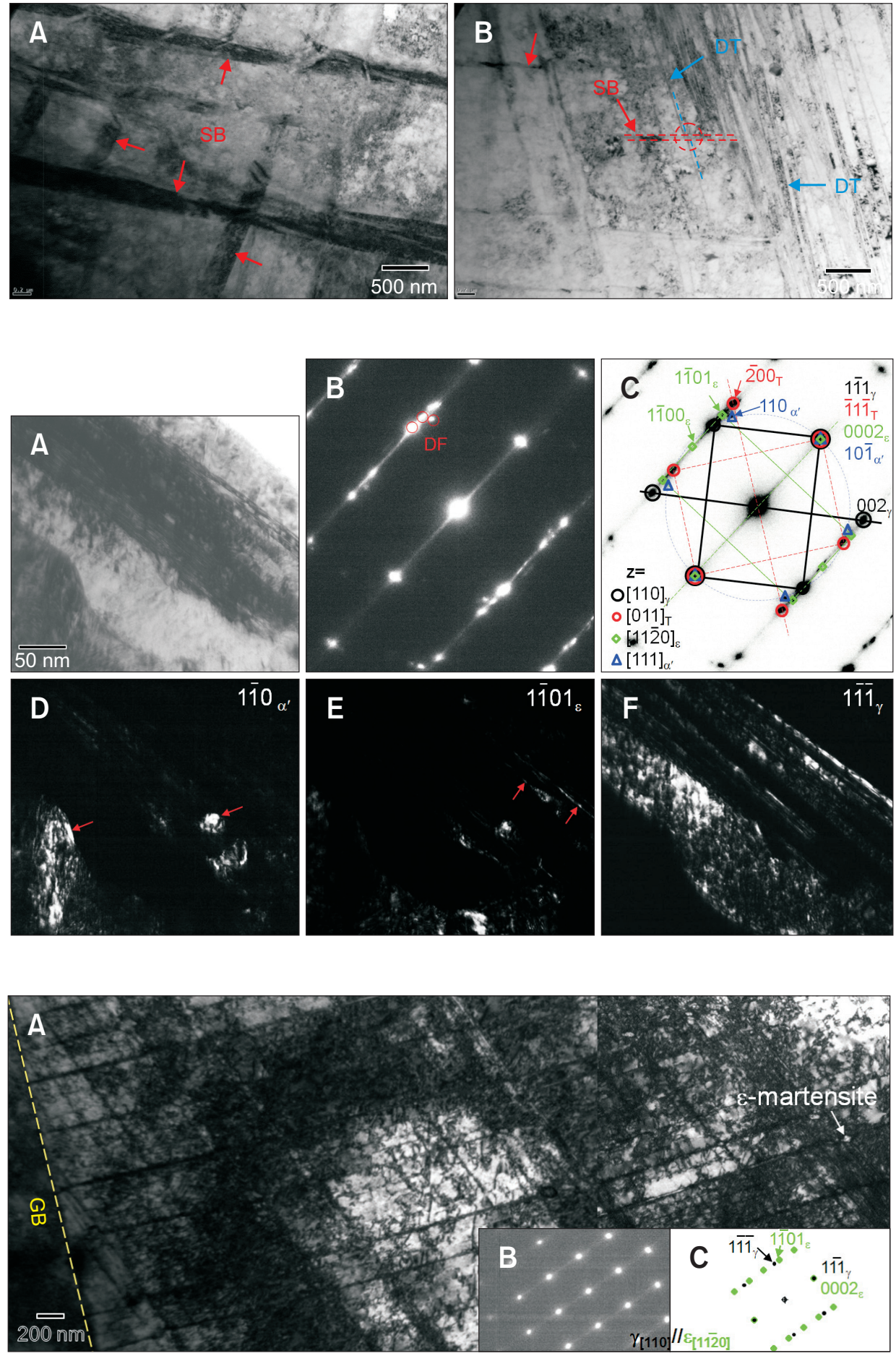

Fig. 12. X-transmission electron microscope bright field images of the air blast shot peening treated specimen at the depth of $\sim 80 \mu \mathrm{m}$ : typical morphologies of the shear band (A), the shear band cut through the DT (B). SB, shear band; DT, deformation twin.

Fig. 13. X-transmission electron microscope (TEM) images of the air blast shot peening treated specimen at the depth of $\sim 15 \mu \mathrm{m}$ : bright field TEM (A), selected area diffraction pattern (B), and corresponding index pattern (C), DF TEM images (D-F), corresponding to the diffracted spots of $\alpha^{\prime}, \varepsilon$, and $\gamma$ in Fig. 13B, respectively. DF, dark field.

Fig. 14. X-transmission electron microscope (TEM) images of the ultrasonic shot peening treated specimen at the depth of $\sim 110 \mu \mathrm{m}$ : bright field TEM (A), selected area diffraction pattern (SADP) (B), and corresponding simulated SADP (C). GB, grain boundary. 


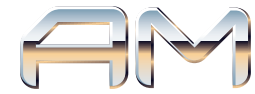

the SB may cut through the DT and would make the torsion of the original DF, as marked in Fig. 12B. The corresponding DF images show that the formation of two individual grains to be due to the cut by the SB (results not shown here).

At a depth of $\sim 15 \mu \mathrm{m}$, the formation of $\alpha^{\prime}$-martensite is observed. Fig. 13 is a set of TEM images recorded $\sim 15 \mu \mathrm{m}$ away from the treated surface of the ABSP treated specimen. Fig. $13 \mathrm{~A}$ shows the further developed DT with a thickness and spacing of 10 to $20 \mathrm{~nm}$. Fig. 13B and C are the SADPs and the indexed SADPs, respectively, showing the $\gamma, \mathrm{T}, \varepsilon$, and $\alpha^{\prime}-$ martensite with the zone axis of $[110]_{\gamma} / /[011]_{\mathrm{T}} / /[11 \overline{2} 0]_{\varepsilon} / /$ $[111]_{\alpha^{*}}$. The orientation is the well-known K-S (KurdjumovSachs) relationship, i.e., the $[110]_{\gamma} / /[111]_{\alpha^{\prime}}$ of fcc and bcc lattices. Fig. 13D-F are the DF images of the $\alpha^{\prime}, \varepsilon$, and $\gamma$, which were obtained from the marked diffracted spots in Fig. 13B, respectively. The formation of island-shaped $\alpha^{\prime}$-martensite $(\sim 30 \mathrm{~nm})$ is observed within the T- $\gamma$ lamellae (Fig. 13D). This is probably due to the fragmentation of the DTs (Chen et al., 2011). Fig. 13E shows that the $\varepsilon$-martensite is still visible at the current depth in which the size and location seem to be similar to the previous one (Fig. 10E). Fig. 13F shows the developed T- $\gamma$ lamellae structure to be in the size range of 10 to $30 \mathrm{~nm}$.

When the depth decreases further to the top-most surface,
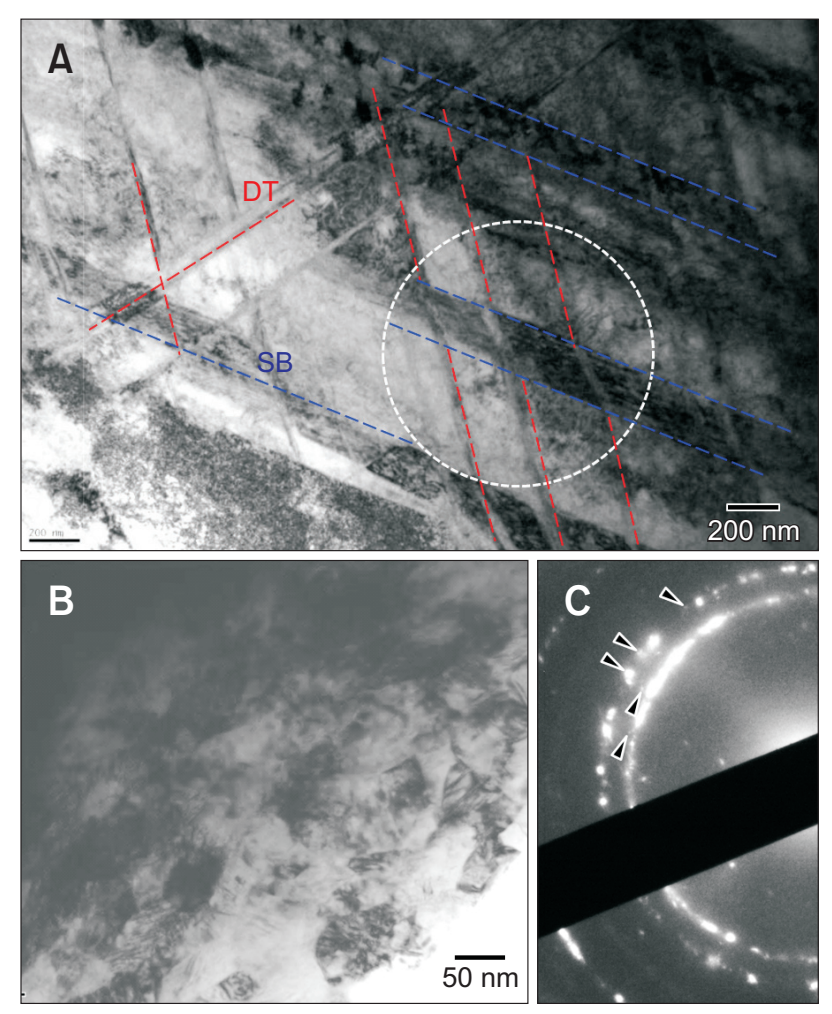

Fig. 15. X-transmission electron microscope bright field and dark field images of the ultrasonic shot peening treated specimen at the depth of $\sim 50 \mu \mathrm{m}(\mathrm{A})$, and $\sim 10 \mu \mathrm{m}$ (B) with selected area diffraction pattern (C). DT, deformation twin; SB, shear band. the microstructure is similar to that in Fig. 4A, the developed refined grain, containing the refined $\gamma$ and newly formed twin, $\varepsilon$ - and $\alpha^{\prime}$ - martensite.

\section{Microstructural evolution in the USP specimen}

At the depth of $\sim 270 \mu \mathrm{m}$ from the topmost surface, the dominant microstructure is the PDA within the original coarse grain, which is very similar to Fig. 9A. At about $\sim 110 \mu \mathrm{m}$, the intersections of the DT are frequently observed within original coarse grain as seen in Fig. 14A. In addition, there is still a high density of PDA within the DT intersection areas. Corresponding SADP (Fig. 14B) shows spots of $\gamma$ matrix with diffuse streaks perpendicular to the direction of the PDAs, covering up about the same region of the spots of $\varepsilon$-martensite, as indicated by the simulation analysis of the SADP as shown in Fig. 14C. The fact that the orientation of the PDAs are [110] indicates that PDAs are formed via deformation on the slip system $\{111\}<110>$. The stacking faults formed this way would result in a formation of hcp crystal and formation of $\varepsilon$-martensite (Lee et al., 2013), though the diffraction does not quite show this obviously because of the aforementioned reason. In Fig. 14A, $\varepsilon$-martensite $(\sim 50 \mathrm{~nm})$ is seen in the DT intersections as marked. The orientation relationship of $\gamma$ and $\varepsilon$ is identified as $[110]_{\gamma} / /[110]_{\varepsilon}$, which is the same as the previous ABSP treated one.

At decreased depth of $\sim 50 \mu \mathrm{m}$, the formation of SB, which cut through the DT, is the dominant structure as shown in Fig. 15A. Fig. 15B and C show the TEM BF image with the corresponding SADP at the depth of $\sim 10 \mu \mathrm{m}$ from the top-most surface. A developed nano-grain with random misorientation is clearly seen in Fig. 15B and C. Careful examination of the SADP found that it was very similar to Fig. 5C. The broad and scattered diffraction spots (as marked) around the rings suggest the formation of $\alpha^{\prime}$-martensite at this depth. When the depth to the topmost surface is decreased further, the microstructures are very similar to those in Fig. $5 \mathrm{~A}$ and $\mathrm{B}$.

\section{Microstructural evolution in the UNSM specimen}

Below $\sim 200 \mu \mathrm{m}$, the PDA in high density is observed as shown in the typical TEM micrographs at the depth of the UNSM peened specimens (Fig. 16A). Clearly, PDA, DT intersection (confirmed by Fig. 16B) and $\varepsilon$-martensite can be seen. The characterization of the $\varepsilon$-martensite is dependent on the satellite diffraction spots as shown in Fig. 16C. Unlike the $\varepsilon$-martensite plate/island in the DT or DT intersection of the ABSP and USP treated specimens, the $\varepsilon$-martensite appears as the long-plate within the DT (marked in Fig. 16A) in the UNSM treated specimen.

Fig. 16D and E are TEM images at a depth of $\sim 120 \mu \mathrm{m}$ from the treated surface of the UNSM treated specimen. It can be seen that the formation of the SB cut through the DT. The 

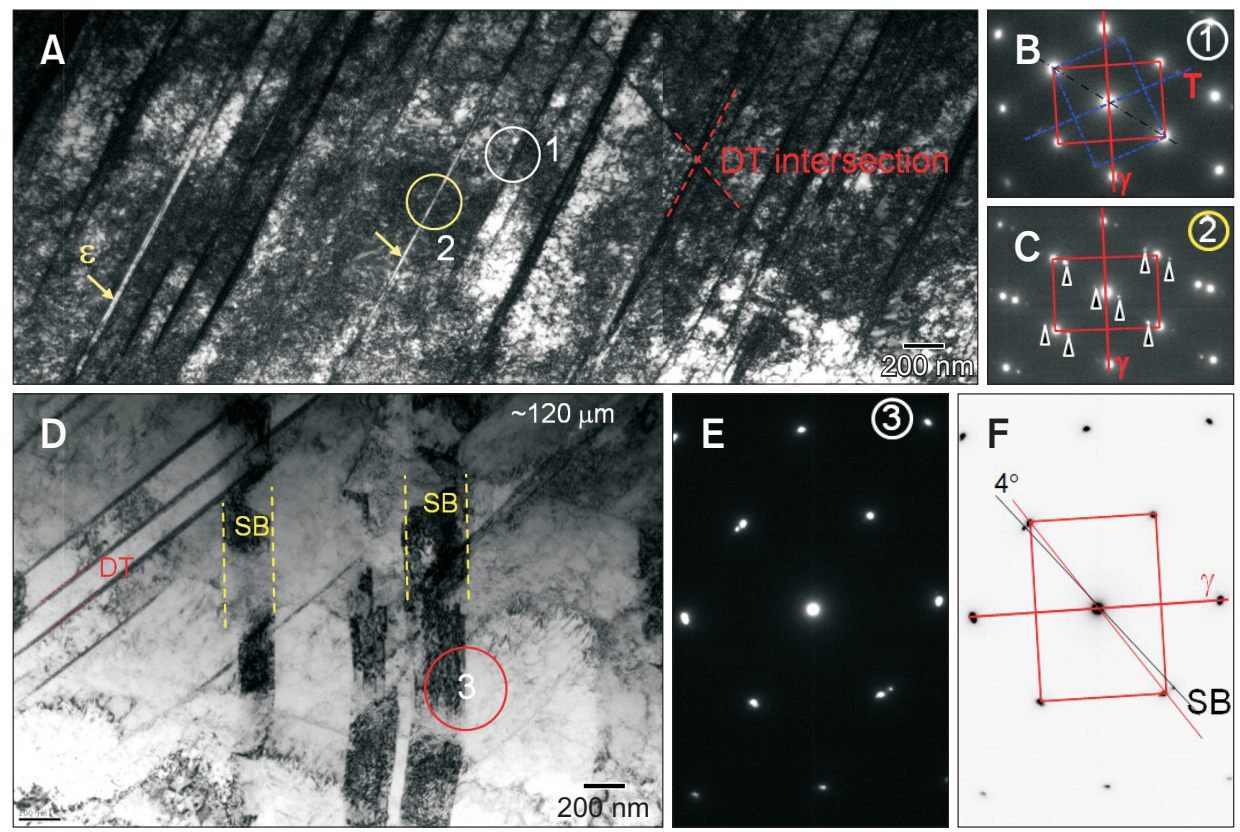

Fig. 16. X-transmission electron microscope (TEM) images of the ultrasonic nanocrystalline surface modification treated specimen at the depth of $\sim 200$ $\mu \mathrm{m}$ (A-C), and $\sim 120 \mu \mathrm{m}$ (B). Bright field TEM (A), Fig. 16B and $C$ are the indexed selected area diffraction pattern (SADP) of the " 1 " and " 2 " marked regions in Fig. 16A. Bright field TEM (D), Fig. 16E is the SADP of region "3" in Fig. 16D, and Fig. $16 \mathrm{~F}$ is the indexed SADP of Fig. 16E. DT, deformation twin; SB, shear band.
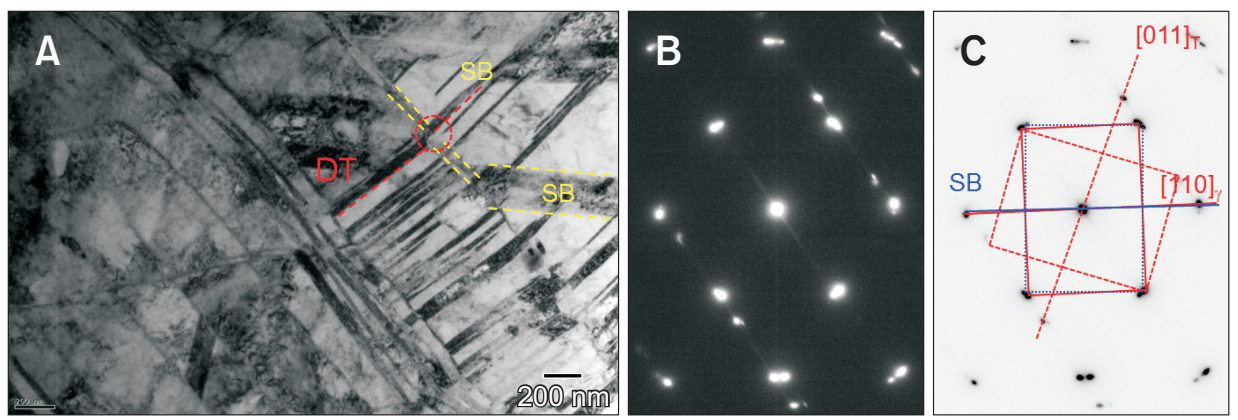

Fig. 17. X-transmission electron microscope (TEM) images of the ultrasonic nanocrystalline surface modification treated specimen at $\sim 90 \mu \mathrm{m}$ from the surface: bright field TEM image (A), corresponding selected area diffraction pattern (B) with indices (C). DT, deformation twin; SB, shear band.
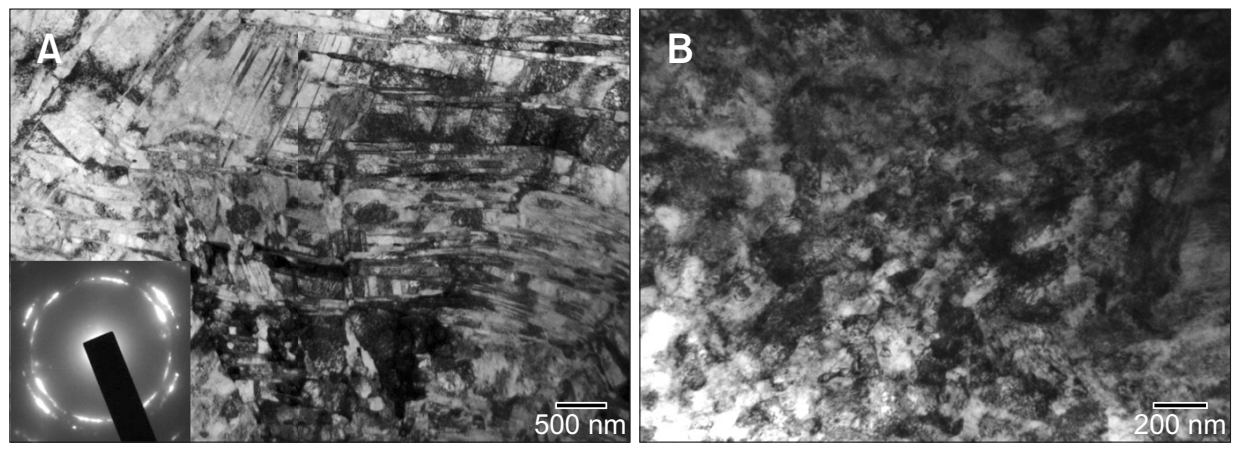

Fig. 18. X-transmission electron microscope bright field images of the ultrasonic nanocrystalline surface modification treated specimen at the depth of $\sim 20 \mu \mathrm{m}$ (A) and $\sim 10 \mu \mathrm{m}$ (B). Inset in Fig. 18A is the corresponding selected area diffraction pattern.

corresponding SADP (Fig. 16E and F) show that the SB has a $\sim 4^{\circ}$ misorientation angle with $\gamma$. Some authors like to define this kind of SB as the subgrain boundary or shear band due to the low misorientation angle ( $\mathrm{Liu} \& \mathrm{Lu}, 2000$; Xue et al., 2007). Similar microstructures are observed at a depth of $\sim 90$ $\mu \mathrm{m}$ as shown in Fig. 17.

As $\sim 20 \mu \mathrm{m}$ from the topmost surface (Fig. 18A), the main microstructures are the DT-DT intersection, DT- $\gamma$ lamella with SB and dispersed newly formed $\varepsilon$ - and $\alpha^{\prime}$-martensite (inset SADP). At still shallower depths, $\sim 10 \mu \mathrm{m}$, the structures are formed in nanograins with random misorientation as shown in Fig. 18B.

\section{Microstructural Refinement Mechanism}

After shot peening, strain (rate) increases as one goes closer to the topmost surface. The depth-dependent microstructures 
are, in terms of the PDA, DT-DT intersectional, $\varepsilon^{-}$, SB and $\alpha^{\prime}$-martensite in the sequence of the strain. From this, a grain refinement mechanism for SS304 steel is deduced, as is illustrated in Fig. 19. Each step will be discussed based on the TEM observations.

Prior to shot peening, the original coarse grain (state 1 in Fig. 19) contains a few stacking faults, dislocations and annealing twins, as shown in Fig. 3. The first change to the structure is the introduction of high density of dislocations, which rearrange to form the PDA (state 2 of Fig. 19). The formation of PDA rather than a dense dislocation wall is attributed to the low SFE effect (Zhang et al., 2003), so that slips occur mainly on the $\{111\}$ planes, and the dislocations arrange themselves into planar arrays on their primary slip planes. The formation of DT and DT-DT intersections (state 3 of Fig. 19) is another process which was believed to compete with dislocation slip, which can also be seen in the TEM observations (for example, Fig. 9B, Fig. 14A, and Fig. 16A). In the present work, however, the DT is considered to be the decisive feature of the shot peened specimens, in which the density and thickness increase with decreasing depth from the top treated surface, thus, owing to the increase of strain closer to the surface. Formation of DT at low strain (greater depths) is similar to the observations in other low SFE materials (Liu \& Lu, 2000; Tao et al., 2004; Wang et al., 2006; Yan et al., 2012). With increasing strain, the formation of the $\varepsilon$-martensite within the DT and/or at the DT intersections is seen (state 4 of Fig. 19). The formation of the nano-sized $\varepsilon$-martensite may cut the DT into several parts as shown in the TEM images of Fig. 10E. In addition, a high deformation by shot peening resulted in a high density of DTs in a typical DT- $\gamma$ lamellar structure with thickness/intervals of 50 to 100 nm, as shown in Fig. 10D, Fig. 12B, Fig. 13A and F, Fig. 17A, and Fig. 18A. Formation of $\varepsilon$-martensite is usually observed in deformed austenitic stainless steel with low SFE (Lee \& Lin, 2000; Nakada et al., 2010; Chen et al., 2011), and that may suggest a path for the formation of the $\alpha^{\prime}$-martensite, namely, $\gamma \rightarrow \varepsilon \rightarrow \alpha^{\prime}$ instead of $\gamma \rightarrow \alpha^{\prime}$ directly (Xue et al., 2007; Chen et al., 2011). At shallower depths the SB begin to form (state 5 of Fig. 19). The SB has morphologies similar to those of the DT, however, with a totally different orientation relationship with $\gamma$ (Fig. 16 and 17). The formation of SB might be related to the accumulation of the dislocations, because within the lamellar structure, the dislocation density is still very high (for example, Fig. 12A, Fig. 15A, and Fig. 16B). In this study, rather than the directional DTs cutting other DTs/DT intersections (Lu et al., 2010), the SBs cutting through the DTs/DT intersections are more frequently observed, indicating that the shear bands cutting the grains and DTs can be the dominant refinement mechanism at a high deformation (Fig. 12B, Fig. 15A, and Fig. 17A).

At shallower depths (i.e., at high deformation), the formation of $\alpha^{\prime}$-martensite islands is preferred to the lamellar structure (state 6 in Fig. 19). Due to the high strain near the surface, the on-site formation of the deformation microstructure (especially, SB and $\varepsilon$-martensite) will gradually distort the original and as-developed (i.e., SB, DT) grain boundaries (state 7 in Fig. 19), and eventually transform to equiaxal refined grains by further development of the newly formed grain boundaries (state 8 in Fig. 19).
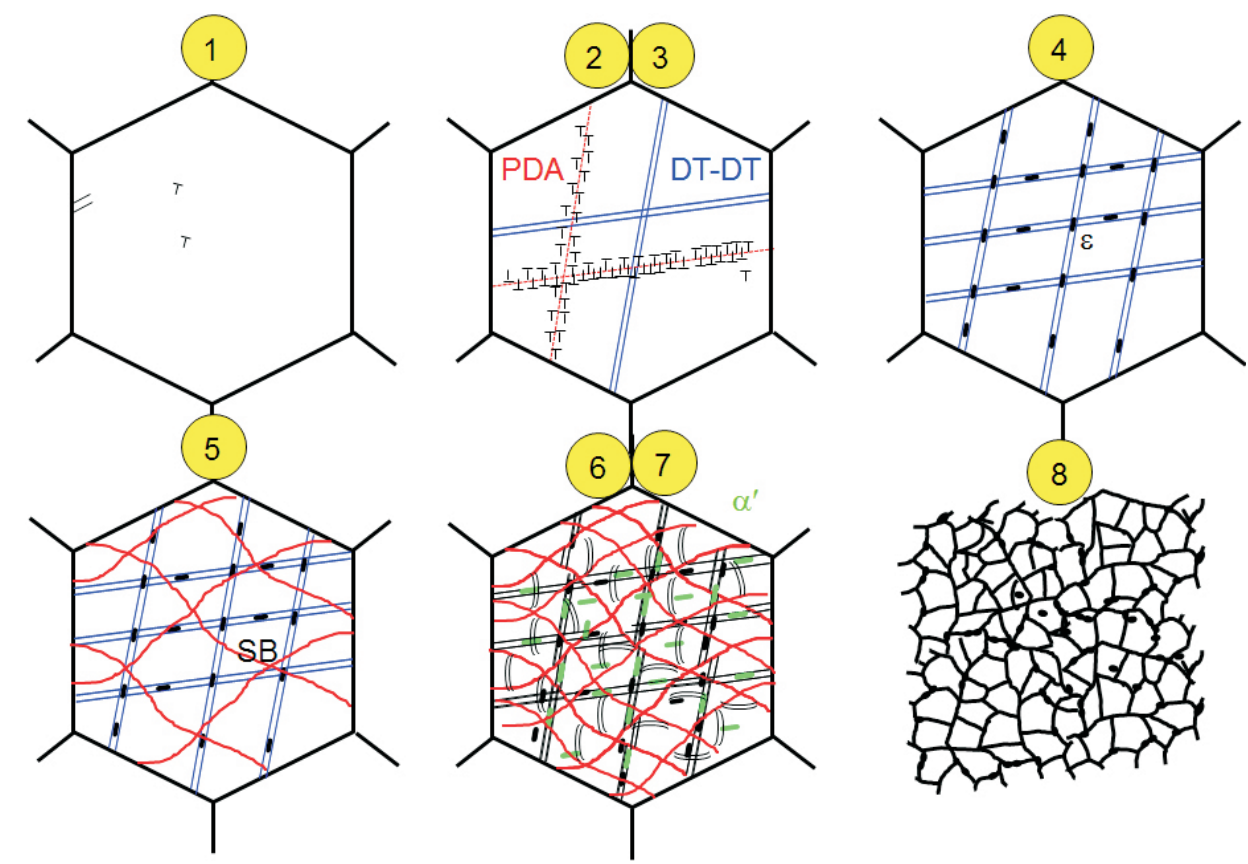

Fig. 19. Schematic diagrams showing the grain refinement mechanism of the SS304 upon various shot peening. PDA, planar dislocation arrays; DT, deformation twin; $\mathrm{SB}$, shear band. 
The morphologies, crystallographic orientational relationships and strain-dependence of the microstructures are somewhat similar for all peening methods. The calculation of the strain and strain rate of the shot peened specimens is not feasible, or beyond the scope of this work; however, we suggest that the depth-dependent deformation microstructures of the various shot peened specimens are 1) low-strain layer of the PDA: DT-DT intersection; 2) mid-strain layer: $\varepsilon$-martensite formation and SB, and 3) high-strain layer; $\alpha^{\prime}$-martensite formation.

\section{SUMIMARY}

In this work, austenitic $(\gamma)$ stainless steel (SS304) was subjected to ABSP, USP, or UNSM peening in order to elucidate the comprehensive deformation structures and plastic deformation induced grain refinement mechanisms. After treatment, the depth-dependent deformation microstructures including PDA, DT, SB, DT-DT/SB intersection, and $\varepsilon$ - and $\alpha^{\prime}-$ martensite were characterized by the plan-view and X-TEM. Our findings are:

1) A dimpled surface, in $\mu \mathrm{m}$-scale, was observed in ABSP and USP treated specimens, whereas a snake-speckle surface was formed after UNSM treatment.
2) Deformation structures varied with the depth from the top treated surface (strain):

- Lower (strain) layer: PDA, DT

- Middle (strain) layer: SB, DT-SB/DT intersection, $\varepsilon$-martensite

- Top (strain) layer: $\alpha^{\prime}$-martensite formation

3) Strain induced $\varepsilon^{-}$and $\alpha^{\prime}$-martensite phases were preferentially formed at the DT, DT-DT/SB intersections.

4) The grain refinement sequence/mechanism is: 1) grains sub-division by the grain boundaries introduced by the formation of the DT and DT/SB-intersections, and 2) formation of the nano-sized $\varepsilon$ - and $\alpha^{\prime}$-martensite.

5) The strain or amount of deformation appears to be the dominant effect on the development of deformation microstructure, such that there was no discernible difference in the deformation microstructure and grain refinement mechanisms among the ABSP, USP, and UNSM treatment otherwise.

\section{CONFLICT OF INTEREST}

No potential conflict of interest relevant to this article was reported.

\section{REFERENCES}

Amanov A, Cho I S, Pyoun Y S, Lee C S, and Park I G (2012) Microdimpled surface by ultrasonic nanocrystal surface modification and its tribological effects. Wear 286-287, 136-144.

Chen A Y, Ruan H H, Wang J, Chan H L, Wang Q, Li Q, and Lu J (2011) The influence of strain rate on the microstructure transition of 304 stainless steel. Acta Mater. 59, 3697-3709.

Datta K, Delhez R, Bronsveld P M, Beyer J, Geijselaers H J M, and Post J (2009) A low-temperature study to examine the role of $\varepsilon$-martensite during strain-induced transformations in metastable austenitic stainless steels. Acta Mater. 57, 3321-3326.

Du H, Wei Y, Lin W, Hou L, Liu Z, An Y, and Yang W (2009) One way of surface alloying treatment on iron surface based on surface mechanical attrition treatment and heat treatment. Appl. Surf. Sci. 255, 8660-8666.

Gleiter H (2000) Nanostructured materials: basic concepts and microstructure. Acta Mater. 48, 1-29.

Guo F A, Trannoy N, and Lu J (2004) Microstructural analysis by scanning thermal microscopy of a nanocrystalline Fe surface induced by ultrasonic shot peening. Superlattices Microstruct. 35, 445-453.

He Y, Li K, Pyoun Y S, Cho I S, Lee C S, Park I G, Song J I, Yang C W, Lee $\mathrm{J} \mathrm{H}$, and Shin K (2014) Characterization of the nano-scale surface layer of a tempered martensitic steel synthesized by ultrasonic nanocrystalline surface modification treatment. Sci. Adv. Mater. 6, 2260-2268.

Hong S J, Hwang G H, Han W K, and Kang S G (2011) Cyclic oxidation behavior of Pt-modified aluminide coating treated with ultrasonic nanocrystal surface modification (UNSM) on Ni-based superalloy. Surf. Coat. Technol. 205, 2714-2723.

Kruml T, Polák J, and Degallaix S (2000) Microstructure in 316LN stainless steel fatigued at low temperature. Mater. Sci. Eng. A 293, 275-280.

Lee H, Kim D, Jung J, Pyoun Y, and Shin K (2009) Influence of peening on the corrosion properties of AISI 304 stainless steel. Corro. Sci. 51, 2826-2830.

Lee T H, Ha H Y, Kang J Y, Moon J, Lee C H, and Park S J (2013) An intersecting-shear model for strain-induced martensitic transformation. Acta Mater. 61, 7399-7410.

Lee W S and Lin C F (2000) The morphologies and characteristics of impact-induced martensite in $304 \mathrm{~L}$ stainless steel. Scripta Mater. 43, 777-782.

Liu J L G and Lu K (2000) Surface nanocrystallization of 316L stainless steel induced by ultrasonic shot peening. Mater. Sci. Eng. A 286, 9195.

Liu X C, Zhang H W, and Lu K (2013) Strain-induced ultrahard and ultrastable nanolaminated structure in nickel. Science 342, 337-340.

Lu J Z, Luo K Y, Zhang Y K, Sun G F, Gu Y Y, Zhou J Z, Ren X D, Zhang X C, Zhang L F, Chen K M, Cui C Y, Jiang Y F, Feng A X, and Zhang L (2010) Grain refinement mechanism of multiple laser shock processing impacts on ANSI 304 stainless steel. Acta Mater. 58, 5354-5362.

Lu K and Hansen N (2009) Structural refinement and deformation mechanisms in nanostructured metals. Scripta Mater. 60, 1033- 
1038.

Lu K and Lu J (2004) Nanostructured surface layer on metallic materials induced by surface mechanical attrition treatment. Mater. Sci. Eng. A 375-377, 38-45.

Lu L, Shen Y, Chen X, Qian L, and Lu K (2004) Ultrahigh strength and high electrical conductivity in copper. Science 304, 422-426.

Mayer T, Balogh L, Solenthaler C, Müller Gubler E, and Holdsworth S R (2012) Dislocation density and sub-grain size evolution of $2 \mathrm{CrMoNiWV}$ during low cycle fatigue at elevated temperatures. Acta Mater. 60, 2485-2496.

Meyers M A, Mishra A, and Benson D J (2006) Mechanical properties of nanocrystalline materials. Prog. Mater. Sci. 51, 427-556.

Nakada N, Ito H, Matsuoka Y, Tsuchiyama T, and Takaki S (2010) Deformation-induced martensitic transformation behavior in coldrolled and cold-drawn type 316 stainless steels. Acta Mater. 58, 895903.

Roland T, Retraint D, Lu K, and Lu J (2006) Fatigue life improvement through surface nanostructuring of stainless steel by means of surface mechanical attrition treatment. Scripta Mater. 54, 19491954.

Suh C M, Song G H, Suh M S, and Pyoun Y S (2007) Fatigue and mechanical characteristics of nano-structured tool steel by ultrasonic cold forging technology. Mater. Sci. Eng. A 443, 101-106.

Tan L, Ren X, Sridharan K, and Allen T R (2000) Effect of shot-peening on the oxidation of alloy $800 \mathrm{H}$ exposed to supercritical water and cyclic oxidation. Corro. Sci. 50, 2040-2046.

Tao N R, Wu X L, Sui M L, Lu J, and Lu K (2004) Grain refinement at the nanoscale via mechanical twinning and dislocation interaction in a nickel-based alloy. J. Mater. Res. 19, 1623-1629.

Tao Z B W N R, Tong W P, Sui M L, Lu J, and Lu K (2002) An investigation of surface nanocrystallization mechanism in Fe induced by surface mechanical attrition treatment. Acta Mater. 50, 4603-4616.

Tong W P, Tao N R, Wang Z B, Lu J, and Lu K (2003) Nitriding iron at lower temperatures. Science 51, 686-688.

Umemoto M, Todaka Y, and Tsuchiya K (2003) Formation of nanocrystalline structure in steels by air blast shot peening. Mater. Trans. 44, 1488-1493.

Wang K, Tao N R, Liu G, Lu J, and Lu K (2006) Plastic strain-induced grain refinement at the nanometer scale in copper. Acta Mater. 54, 52815291.

Xue Q, Cerreta E, and Grayiii G (2007) Microstructural characteristics of post-shear localization in cold-rolled $316 \mathrm{~L}$ stainless steel. Acta Mater. 55, 691-704.

Yan F K, Liu G Z, Tao N R, and Lu K (2012) Strength and ductility of 316L austenitic stainless steel strengthened by nano-scale twin bundles. Acta Mater. 60, 1059-1071.

Yu H, Dong J L, Yoo D H, Shin K, Jung J S, Pyoun Y, and Cho I (2009) Effect of ultrasonic and air blast shot peening on the microstructural evolution and mechanical properties of SUS304. J. Korean Phys. Soc. 54, 1161-1166.

Zhang H W, Hei Z K, Liu G, Lu J, and Lu K (2003) Formation of nanostructured surface layer on AISI 304 stainless steel by means of surface mechanical attrition treatment. Acta Mater. 51, 1871-1881.

Zhong C, Liu L, Wu Y, Deng Y, Shen B, Shu B, and Hu W (2010) Diffusion behavior of aluminum in the surface layer of iron processed by shot peening. Mater. Lett. 64, 1407-1409. 